\title{
REGENERAÇÃO DE PLANTAS APÓS FUSÃO DE PROTOPLASTOS DE TANGELO 'PAGE' E TORANJA 'LAU TAU'
}

\author{
DAYSE CRISTINA DE CARVALHO², FRANCISCO DE ASSIS ALVES MOURÃO FILHO ${ }^{3}$, \\ BEATRIZ MADALENA JANUZZI MENDES ${ }^{4}$, CARLOS ROBERTO DE CARVALHO $^{5}$
}

RESUMO - Buscou-se a hibridação somática entre tangelo 'Page' e toranja 'Lau Tau' visando à produção de porta-enxerto semelhante à laranja-azeda, por esta espécie ser considerada um provável híbrido entre $C$. reticulata e C. grandis. Após isolamento, fusão e cultivo de protoplastos, obtiveram-se brotações que foram enxertadas in vitro, em laranja 'Hamlin'. Dezessete plantas foram aclimatizadas em casa de vegetação. A análise de citometria de fluxo confirmou a constituição diplóide dessas plantas. Marcadores moleculares RAPD das plantas regeneradas apresentaram padrão de bandas similar ao de tangelo 'Page'. Entretanto, todas as plantas apresentaram conformação fenotípica diferente dos genitores.

Termos para indexação: citros, cultura de tecidos, hibridação somática, porta-enxerto, melhoramento genético.

\section{PLANT REGENERATION AFTER PROTOPLAST FUSION OF 'PAGE' TANGELO AND 'LAU TAU' PUMMELO}

\begin{abstract}
This work aimed to produce somatic hybrid between 'Page' tangelo and 'Lau Tau' pummelo in an attempt to regenerate a similar rootstock to sour orange, because this species is considered a probable hybrid between C. reticulata and C. grandis. After protoplast isolation, fusion and culture regenerated shoots were in vitro grafted on 'Hamlin' sweet orange. Seventeen plants were acclimatized in a greenhouse. Citometric flow analyses revealed that all plants are diploid. RAPD molecular markers of regenerated plants had the same pattern as compared to 'Page' tangelo. However, all plants had phenotypic traits different from both genitors.

Index terms: citrus, genetic improvement, rootstock, somatic hybridization, tissue culture.
\end{abstract}

\section{INTRODUÇÃO}

Híbridos interespecíficos de citros podem ser obtidos via cruzamentos controlados, mas com limitações, devido a aspectos da biologia reprodutiva do gênero, como o longo período de juvenilidade, presença de embriões nucelares, incompatibilidade e esterilidade sexual, alta heterozigose (Grosser \& Gmitter Junior, 1990). A utilização de ferramentas biotecnológicas podem auxiliar na superação destas limitações do melhoramento genético convencional, contribuindo, assim, para o desenvolvimento de novas cultivares. Uma destas técnicas é a hibridação somática, a partir da qual podem ser produzidos híbridos interespecíficos, buscando combinar características desejáveis dos genitores em uma mesma planta (Grosser \& Gmitter Junior, 2005).

Os porta-enxertos de citros oriundos da hibridação somática têm levado a ganhos significativos na qualidade dos frutos e na produção de sementes, além de redução do porte das plantas. Verificou-se também que o híbrido somático laranja-azeda + limão 'Cravo' tem demonstrado tolerância ao vírus da tristeza dos citros (CTV) (Grosser \& Chandler, 2003).

Protoplastos derivados de folhas de citros não têm potencial embriogênico e não sofrem morfogênese nas condições-padrão de cultivo (Grosser \& Gmitter Junior, 1990).
Entretanto, muitas plantas diplóides, morfologicamente idênticas ao genitor, cujos protoplastos são de origem foliar, foram regeneradas após fusões simétricas interespecíficas entre espécies diplóides. Análises destas plantas com base em marcadores moleculares têm indicado que as mesmas são híbridos aloplásmicos ou cíbridos, apresentando genoma nuclear do genitor não-embriogênico e o mtDNA do genitor embriogênico (Moreira et al., 2000; Liu et al., 2002).

Até recentemente, o valor agronômico dos cíbridos de citros era pouco conhecido, pois características horticulturais importantes, associadas com genomas de organelas, ainda não haviam sido identificadas (Grosser et al., 2000); no entanto, a avaliação de cíbridos de tangerinas e laranjas-doces no campo tem mostrado variação significativa em características agronômicas importantes, incluindo a época de maturação do fruto e conteúdo de sementes, indicando que a cibridização é uma fonte potencial de variação genética para o melhoramento de variedades de citros (Grosser \& Gmitter Junior, 2005).

Buscou-se, neste trabalho, a hibridação somática entre tangelo 'Page' e toranja 'Lau Tau' visando à produção de portaenxerto semelhante à laranja-azeda, por esta espécie ser considerada um híbrido provável entre $C$. reticulata e $C$. grandis (Nicolosi et al., 2000).

\footnotetext{
(Trabalho 163-06). Recebido em: 20-10-2006. Aceito para publicação em : 20-04-2007.

${ }^{2}$ Eng $^{\mathrm{a}}$ Agra , MSc., Aluna do PPG em Fitotecnia (Doutorado), Universidade de São Paulo, ESALQ, Piracicaba-SP.

${ }^{3}$ Eng $^{\circ}$. Agr ${ }^{\circ}$, Dr., Professor Associado. Universidade de São Paulo, ESALQ, Departamento de Produção Vegetal, Caixa Postal 9, 13418-900, PiracicabaSP. Autor Correspondente. famourao@esalq.usp.br

${ }^{4}$ Eng $^{\mathrm{a}}$. Agra ${ }^{\mathrm{a}}$, Dra ${ }^{\mathrm{a}}$, Professora Associada. Universidade de São Paulo, CENA, Laboratório de Biotecnologia Vegetal, Piracicaba-SP.

${ }_{5}^{5}$ Eng.Agr.,Prof.Adjunto, Universidade Federal de Viçosa, Departamento de Biologia Geral, Viçosa-MG
} 


\section{MATERIAL E MÉTODOS}

Isolamento, fusão e cultivo de protoplastos e regeneração de plantas

Protoplastos de tangelo 'Page' (C. reticulata $\mathrm{x} C$. paradisi) foram isolados de suspensões celulares derivadas de calos embriogênicos, cultivadas em meio de cultura EME ou $\mathrm{H}+$ $\mathrm{H}$, no escuro, a $27^{\circ} \mathrm{C}$ (Grosser \& Gmitter Junior, 1990). Protoplastos de "seedling” de toranja 'Lau Tau' (Citrus grandis) selecionada para a resistência a Phytophthora sp. (Calixto et al., 2003) foram obtidos de folhas jovens de plantas cultivadas em casa de vegetação. Procedimentos relacionados ao isolamento, purificação, fusão e cultivo de protoplastos foram realizados de acordo com protocolos anteriores (Mendes et al., 2001; Costa et al., 2003).

A regeneração de plantas ocorreu por embriogênese somática em meio de cultura EME modificado pela adição de maltose (37 mM) (Benedito et al., 2000). Os embriões formados foram então transferidos para o meio 1500 (Grosser \& Gmitter Junior, 1990). As plântulas originadas foram enxertadas in vitro por garfagem em laranja 'Hamlin' (C. sinensis). As plantas obtidas foram então transferidas para casa de vegetação, sendo cultivadas em substrato comercial.

\section{Análise das plantas regeneradas}

Todas as plantas regeneradas foram caracterizadas morfologicamente pela avaliação da espessura das folhas, formato do limbo e pecíolo foliares e coloração.

A determinação da ploidia foi realizada através da análise de citometria de fluxo, sendo utilizado um citômetro PAS II-III Partec $^{\circledR}$ equipado com lâmpada HBO $100 \mathrm{~W}$ e filtros KG1, BG 38 e CG 435. As suspensões nucleares foram isoladas e coradas com o tampão do kit CyStain UV precise T-DAPI (Partec ${ }^{\circledR}$ ), seguindo as recomendações do fabricante. $\mathrm{O}$ material foi processado com três repetições e analisados pelo software FlowMax ${ }^{\circledR}$ v 2.6 $\left(\right.$ Partec $\left.^{\circledR}\right)$. Não menos que 5.000 núcleos foram analisados, e amostras com coeficiente de variação $(\mathrm{CV})$ acima de $5 \%$ foram descartadas. Os histogramas gerados pelo software foram calibrados para um parâmetro (SSC) e dimensionados no eixo de $\mathrm{X}$ em escala linear com 10 bits.

Para a análise de marcadores moleculares do tipo RAPD, o DNA genômico das plantas regeneradas e de seus genitores foi extraído a partir de folhas, utilizando-se da metodologia de Hoisington et al. (1994). A seleção de 'primers' polimórficos foi realizada a partir de uma avaliação dos produtos de amplificação gerados pelos 'primers' do Kit A-1 a A-20 e AA7 (Operon Technologies). Após seleção, os 'primers' OPA1, OPA2, OPA3, OPA7, OPA8 e OPA9 foram utilizados em reações de PCR na avaliação das plantas regeneradas. A reação da PCR, incluindo a amplificação, separação e análise dos produtos, foi realizada de acordo com protocolos anteriores, com, pelo menos, três repetições para cada 'primer' selecionado (Costa et al., 2003).

\section{RESULTADOS E DISCUSSÃO}

A fusão de protoplastos envolvendo tangelo 'Page' e toranja 'Lau Tau' resultou na regeneração de 17 plantas, as quais foram enxertadas in vitro sobre porta-enxerto laranja 'Hamlin', devido ao fato de não terem desenvolvido sistema radicular adequado. A combinação Citrus sinensis + Clausena lansium também apresentou dificuldade na formação de raízes, tendo-se associado este fato à assimetria cromossômica, à dupla carga cromossômica ou mesmo eliminação cromossômica ( $\mathrm{Fu}$ et al., 2003)

A análise morfológica das plantas resultantes da fusão de protoplastos de tangelo 'Page' + toranja 'Lau Tau' revelou características completamente diferentes dos genitores, com o ápice da folha arredondado e com tamanho reduzido, além da coloração verde-escura, mesófilo enrugado e ausência de pecíolo alado, característica presente em ambos os genitores (Figura 1). A morfologia dos híbridos simétricos interespecíficos e intergenéricos é, geralmente, intermediária a dos genitores. Características, como folhas mais espessas, arredondadas, normalmente mais escuras e com pecíolo alado maior ou intermediário aos parentais e glândulas de óleo aparentes na face abaxial, podem ser comparadas com os genitores para a comprovação da hibridação (Takami et al., 2004). Plantas com morfologia intermediária têm também sido derivadas de fusões assimétricas. A morfologia de plantas regeneradas a partir do mesmo evento de fusão pode ser diversa, isto é, cada indivíduo gerado pode ser morfologicamente distinto do outro (Liu et al., 2005).

Em citros, a seleção de células híbridas pode ser feita pelo cultivo em elevada concentração de sacarose (0,6 M) (Ohgawara et al., 1985), em concordância com a metodologia empregada neste trabalho. Guo \& Grosser (2005) descrevem que a maioria das plantas regeneradas a partir de experimentos de fusão somática são híbridos somáticos tetraplóides e quando as plantas regeneradas incluem plantas diplóides semelhantes a um ou a ambos os genitores, as que primeiro regeneram, são usualmente híbridos somáticos. Isto sugere que híbridos somáticos são mais vigorosos e têm maior capacidade para a embriogênese comparada com regenerantes do genitor calo embriogênico.

$\mathrm{Na}$ análise por citometria de fluxo das suspensões nucleares obtidas das folhas, os picos de leitura da quantidade de DNA em $\mathrm{G}_{1}$, após a coloração com DAPI, resultaram histogramas com resolução suficiente para confirmar a ploidia, revelando que as plantas regeneradas das fusões de protoplastos de tangelo 'Page'+ toranja 'Lau Tau' tratam-se de indivíduos diplóides $(2 \mathrm{n}=2 \mathrm{x}=18)$ (Figura 2). A ocorrência de diploidia nas plantas regeneradas e semelhança com um dos genitores pode indicar que as mesmas sejam um variante somaclonal da planta doadora de protoplastos de calo embriogênico, ou de um híbrido aloplásmico ou cíbrido (Cabasson et al., 2001).

Pesquisas relacionadas a esse assunto indicam que diversas plantas diplóides foram regeneradas após fusões simétricas entre espécies diplóides. Essas plantas foram denominadas tipo genitor foliar porque eram morfologicamente idênticas à planta doadora de protoplastos de mesófilo utilizado na fusão. Análises subseqüentes dessas plantas, baseadas em marcadores moleculares, indicaram que eram híbridos aloplásmicos ou cíbridos. A maioria dessas plantas surgiu a partir 
de combinações interespecíficas (Liu et al., 2002). Embora a formação de cíbridos através de hibridação somática em Citrus pareça ocorrer somente em combinações de espécies dentro do gênero (Moriguchi et al., 1996), plantas cíbridas da combinação entre Microcitrus papuana e Citrus aurantium foram obtidas (Xu et al., 2004).

Comparado com o DNA nuclear, o modelo de herança do DNA mitocondrial e cloroplastidial é relativamente mais complexo. Para cloroplastos, a transmissão uniparental tem sido predominantemente detectada em muitas combinações, não importando se são intergenéricas ou interespecíficas. A transmissão ao acaso significa que o DNA cloroplastidial pode ser herdado tanto de protoplastos provenientes de mesófilo foliar, quanto de células provenientes de calos embriogênicos. Um exemplo deste fato é descrito por Guo et al. (2004) em três híbridos somáticos tetraplóides de tangelo 'Page' e tangor 'Murcott', cujas análises moleculares mostraram que dois foram idênticos a tangor 'Murcott' e um igual a tangelo 'Page'.

A análise molecular por marcadores RAPD do genoma total das plantas provenientes da fusão de protoplastos de tangelo 'Page' + toranja 'Lau Tau' indica semelhança entre bandas do genitor embriogênico tangelo 'Page' e a planta regenerada para os 'primers' selecionados (Figura 1). Esses resultados sugerem que a planta regenerada tangelo 'Page' + toranja 'Lau Tau' se trata de um variante somaclonal de tangelo 'Page'. A variação somaclonal está presente na maioria das espécies estudadas e tem gerado efeito sobre inúmeras características, sendo as principais: alterações de padrão morfológico, de pigmentação, de crescimento, produção de alcalóides e mudanças na produção e habituação a auxinas e citocininas (Larkin \& Scowcroft, 1981). Ochatt \& Caso (1986) verificaram que pereiras regeneradas a partir de protoplastos diferiram de plantas-modelo micropropagadas, tanto na morfologia das folhas como na capacidade de enraizamento. As causas dessa instabilidade genética é pouco entendida. Entretanto, acredita-se que a instabilidade cromossômica seja uma das principais causas que induzem a variação na cultura de tecidos (Roux et al., 2004).

Para avaliar se a planta regenerada apresenta o genoma nuclear de toranja 'Lau Tau' e o genoma mitocondrial de tangelo 'Page', análises moleculares mais detalhadas devem ser realizadas, utilizando-se de marcadores do tipo RFLP (Restriction Fragment Length Polymorphism) que requerem a hibridização com sondas cloroplastidiais e mitocondriais. Da mesma forma, para afirmar que a planta regenerada se trata de um protoclone variante, uma nova e detalhada análise de RAPD deve ser realizada envolvendo DNA do tangelo 'Page' e da planta regenerada, verificando se há ocorrência de bandas polimórficas.

\section{CONCLUSÕES}

Os protocolos utilizados para isolamento, fusão e cultura de protoplastos, bem como para a regeneração e aclimatização de plantas permitiram a obtenção 17 plantas da combinação entre tangelo 'Page' e toranja 'Lau Tau', com morfologia diferente dos dois genitores envolvidos.

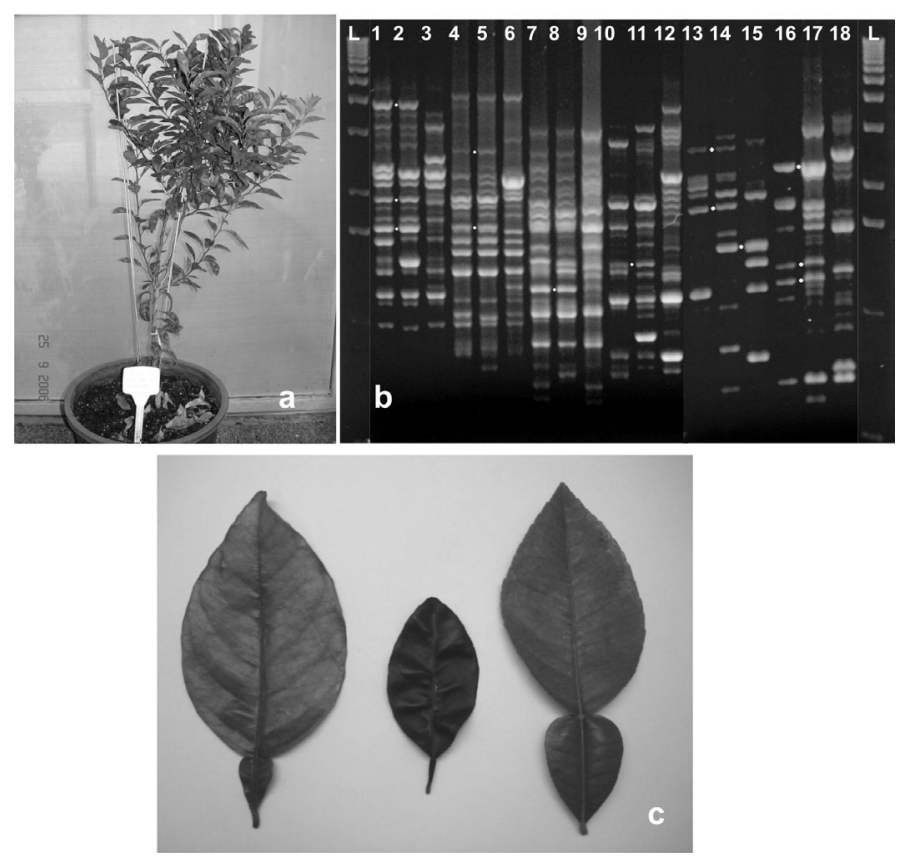

FIGURA 1 - Planta regenerada tangelo 'Page' + toranja 'Lau Tau'. a) Planta mantida em casa de vegetação; b) Análise RAPD: Colunas 1 a 3 = 'primer' OPA 1; colunas 4 a $6=$ 'primer' OPA2; colunas 7 a $9=$ 'primer' OPA3; colunas 10 a 12 = 'primer' OPA7; colunas 13 a $15=$ 'primer' OPA8; colunas 16 a 18 = 'primer' OPA9. Colunas 1, 4, 7, 10 e 13 = tangelo 'Page'; colunas 2, $5,8,11$ e $16=$ Planta regenerada 'Page' + 'Lau Tau'. Colunas 3, 6, 9, 12 e $15=$ toranja 'Lau Tau'. L = Ladder $1 \mathrm{~kb}$; c) Morfologia foliar: tangelo 'Page' (esquerda), planta regenerada 'Page' + 'Lau Tau' (centro) e toranja 'Lau Tau' (direita).
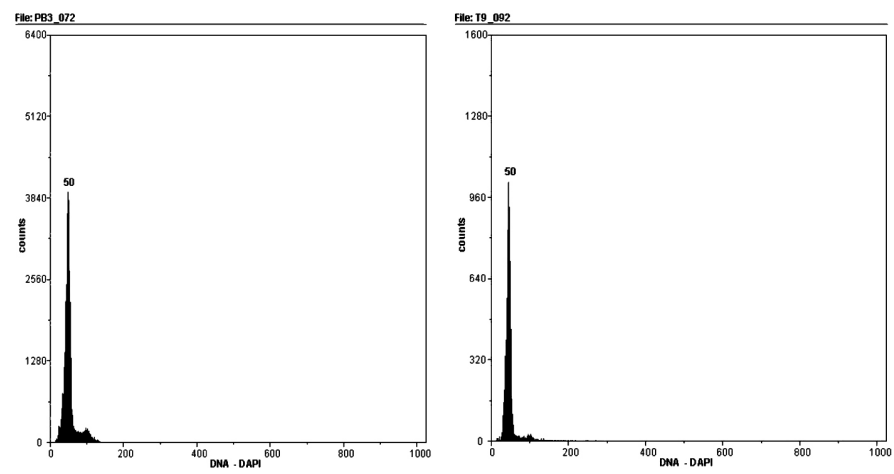

FIGURA 2 - Histogramas obtidos das análises por citometria de fluxo. Padrão diplóide toranja 'Lau Tau' (esquerda). Tangelo 'Page' + toranja 'Lau Tau (direita). 


\section{REFERÊNCIAS}

BENEDITO, V.A.; MOURÃO FILHO, F.A.A.; MENDES, B.M.J. Calogênese, embriogênese somática e isolamento de protoplastos em variedades de laranja doce. Scientia Agricola, Piracicaba, v. 57, p. 33-38, 2000.

CABASSON, C.M.; LURO, F.; OLLITRAULT, P.; GROSSER, J.W. Non-random inheritance of mitochondrial genomes in Citrus hybrids produced by protoplast fusion. Plant Cell Reports, Berlin, v.20, p.604-609, 2001.

CALIXTO, M.C.; MOURÃO FILHO, F.A.A.; MENDES, B.M.J.; PAVAN, A. Seleção de plantas de toranja (C. grandis (L.) Osb.) tolerantes a Phytophthora sp. para uso na hibridação somática. In: CONGRESSO BRASILEIRO DE MELHORAMENTO DE PLANTAS, 2., 2003, Porto Seguro. Anais... Cruz das Almas: Sociedade Brasileira de Melhoramento de Plantas, 2003. p. 1-6.

COSTA, M.A.P.C; MENDES, B.M.J; MOURÃO FILHO, F.A.A. Somatic hybridisation for improvement of citrus rootstock: production of five new combinations with potential for improved disease resistance. Australian Journal of Experimental Agriculture, Collingwood, v.43, n.9, p.11511156, 2003.

FU, C.H.; GUO, W.W.; LIU, J.H.; DENG, X.X. Regeneration of Citrus sinensis (+) Clausena lansium intergeneric triploid and tetraploid somatic hybrids and their identification by molecular markers. In Vitro Cellular \& Developmental Biology Plant, Columbia, v.39, p.360-364, 2003.

GROSSER, J.W.; CHANDLER, J.L. New citrus rootstocks via protoplast fusion. Acta Horticulturae, Wageningen, v. 622, p. 491-497, 2003.

GROSSER, J.W.; GMITTER JUNIOR, F.G. Protoplast fusion and citrus improvement. Plant Breeding Reviews, New Yokr, v.8, p.339-374, 1990.

GROSSER, J.W.; GMITTER JUNIOR, F.G. 2004 SIVB Congress symposium proceedings "Thinking outside the cell": Applications of somatic hybridization in crop improvement, with citrus as a model. In Vitro Cellular \& Developmental Biology Plant, Columbia, v. 41, p.220-225, 2005.

GROSSER, J.M.; OLLITRAUT, P.; OLIVARES-FUSTER, O. Invited review: Somatic hybridization in Citrus: an effective tool to facilitate variety improvement. In vitro Cellular \& Developmental Biology, Columbia, v.36, p.434-449, 2000.

GUO, W.W.; GROSSER, J.W. Somatic hybrid vigor in Citrus: Direct evidence from protoplast fusion of an embryogenic callus line with a transgenic mesophyll parent expressing the GFP gene. Plan Science, Limerick, v.168, p.1541-1545, 2005.

GUO, W.W.; PRASAD, D.; SERRANO, P.; GMITTER JUNIOR, F.G.; GROSSER, J.W. Citrus somatic hybridization with potencial for direct tetraploid scion cultivar development. Journal of Horticultural Science \& Biotechnology, Valência, v.79, n.3, p.100-405, 2004.

HOISINGTON, D.; KHAIRALLAH, M.; GONZÁLEZ-DE-LEÓN, D. Laboratory protocols: CIMMYT Applied Molecular Genetics Laboratory. $2^{\text {nd }}$ ed. México: CIMMYT, 1994. p.88. LARKIN, P.J.; SCOWCROFT, W.R. Somaclonal variation: a novel source of variability from cell cultures for plant improvement. Theoretical and Applied Genetics, New York, v.60, p. 197 214,1981

LIU, J.H.; PANG, X.M.; CHENG, Y.J.; MENG, H.J.; DENG, X.X. Molecular characterization of the nuclear and cytoplasmic genomes of intergeneric diploid plants from cell fusion between Microcitrus papuana and Rough lemon. Plant Cell Reports, Berlin, v.21, p.327-332, 2002.

LIU, J.; XU, X.; DENG, X. Intergeneric somatic hybridization and its application to crop genetic improvement. Plant Cell, Tissue and Organ Culture, Dordrecht, v.82, p. 19-44, 2005.

MENDES, B.J.M.; MOURÃO FILHO, F.A.A.; FARIAS, P.C.M.; BENEDITO, V.A. Citrus somatic hybridization with potencial for improved blight and CTV resistance. In vitro Cellular \& Developmental Biology Plant, Columbia, v.37, n.4, p.256261, 2001.

MOREIRA, C.D.; CHASE, C.D.; GMITTER JUNIOR, F.G.; GROSSER, J.W. Inheritance of organelle genomes in citrus somatic cybrids. Molecular Breeding, Dordrecht, v.6, p.401405, 2000.

MORIGUCHI, T.; HIDAKA, T.; OMURA, M.; MOTOMURA, T.; AKIHAMA, T. Genotype and parental combination influence efficiency of cybrid induction in Citrus by electrofusion. Hortscience, Alexandria, v.31, n.2, p.275-278, 1996.

NICOLOSI, E.; DENG, Z.N.; GENTILE, A.; LA MALFA, S.; CONTINELLA, G.; TRIBULATO, E. Citrus phylogeny and genetic origin of important species as investigated by molecular markers. Theorical and Applied Genetics, Berlim, v.100, p.1155-1166, 2000.

OCHATT, S.J.; CASO, O.H. Shoot regeneration from leaf mesophyll protoplasts of wild pear (Pyrus comunis var pyraster L.). Journal of Plant Physiology, Stuttgart, v.122, p. 243-249, 1986.

OHGAWARA, T.; KOBAYASHI, S.; OGAWARA, E.; UCHIMIYA, J.; ISHII, S. Somatic hybrid plants obtained by protoplast fusion between Citrus sinensis and Poncirus trifoliata. Theoretical and Applied Genetics, Berlim, v.71, p.1-4, 1985.

ROUX, N.S.; STROSSE, H.; TOLOZA, A.; PANIS, B.; DOLEZEL, J. Detecting ploidy level instability of banana embryogenic cell suspension cultures by flow cytometry. In: Jain MS, Swennen R (Eds.). Banana improvement: cellular, molecular biology, and induced mutations. Enfield: Science Publishers, 2004. p. 251-261.

TAKAMI, K.; MATSUMARA, A.; YAHATA, M.; IMAYAMA, T.; KUNITAKE, H.; KOMATSU, H. Production of intergeneric somatic hybrids between round kumquat (Fortunella japonica Swingle) and 'Morita navel' orange (Citrus sinensis Osbeck). Plant Cell Reports, Berlin, v.23, p. 39-45, 2004.

XU, X.; LIU, J.; DENG, X.X. Production and characterization of intergeneric diploid cybrids derived from symmetric fusion between Microcitrus papuana Swingle and sour orange (Citrus aurantium). Euphytica, Dordrecht, v.136, p.115-123, 2004. 